\title{
REVIEW
}

\section{Medical Management of Lower Urinary Tract Symptoms in Men with Benign Prostatic Enlargement}

Michael Marberger

To view enhanced content go to www.advancesintherapy.com Received: February 18, 2013 / Published online: April 12, 2013

(c) The Author 2013. This article is published with open access at Springerlink.com

\section{ABSTRACT}

With the high prevalence of bothersome lower urinary tract symptoms (LUTS) in older men, clinical management has to be fairly simple and straightforward. In the absence of severe problems requiring immediate action, and after excluding possible other etiological factors by a simple diagnostic algorithm, the key parameter for therapeutic decisions is the severity of LUTS, in particular the degree of annoyance and irritation, and prostatic enlargement. Patients with bothersome LUTS request rapid improvement but also worry about possible deterioration, complications, and the need for surgery. With a prostate volume above $30-40 \mathrm{~mL}$ and/or prostate-specific antigen (PSA) serum

M. Marberger $(\bowtie)$

Department of Urology, Medical University Vienna, Waehringer Guertel, Vienna, Austria e-mail: Michael.marberger@A1.net

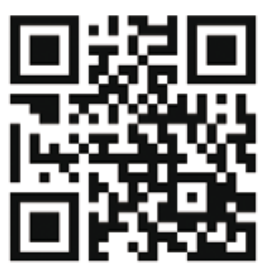

Enhanced content for Advances in Therapy articles is available on the journal web site: www.advancesintherapy.com
$>1.5 \mathrm{ng} / \mathrm{mL}$, the combination of an alpha- 1 blocker with a 5-alpha-reductase inhibitor (5-ARI) should be first-line treatment. With prostates $<30 \mathrm{~mL}$ at baseline the issue whether the prostate really is the culprit becomes central. Given the rapid onset of action of alpha-1 blockers, a 4-6-week trial appears to be a logical approach. If the International Prostate Symptom Score does not improve and storage symptoms prevail, an overactive bladder appears more likely as causative factor and antimuscarinics are the next step. Based on available data this is recommended as add-on medication to the alpha-1 blocker. With no improvement, or increasing postvoid residual the diagnostic algorithm needs to be revisited and more extensive urodynamic evaluation may be needed.

Keywords: 5-alpha-reductase inhibitors; Alpha-1 adrenoceptor antagonists; Benign; Combination therapy; LUTS; Prostate enlargement; Urology

\section{INTRODUCTION}

Lower urinary tract symptoms (LUTS) are a common problem in older men that increases steeply with age $[1,2]$. Approximately $50 \%$ of 
men 70-80 years of age report moderate-tosevere LUTS, with significant bother, and impact on quality of life [3-5]. They can be subcategorized into storage symptoms (frequency, urgency, nocturia, urinary incontinence), voiding symptoms (slow stream, splitting, intermittency, hesitancy, straining, dribble), and postmicturition symptoms (sensation of incomplete emptying, postmicturition dribble), and can be quantified with validated and internationally accepted questionnaires, the International Prostate Symptom Score (IPSS) being most widely used $[6,7]$. Infravesical obstruction by benign prostatic enlargement (BPE) resulting from benign prostatic hyperplasia (BPH) has been assumed to be the main cause of the problem. Indeed, $48-60 \%$ of men $>60$ years of age seen by general practitioners have a clinically enlarged prostate and approximately one third have both moderate-to-severe LUTS and an enlarged prostate [3, 8]. Larger prostate volume has been correlated with more severe LUTS and a higher risk of progression of symptoms and complications [9]. The etiology of LUTS is in fact more complex and multifactorial $[6,7,10]$. Renal factors such as polydipsia or nocturnal polyuria and/or abnormal bladder function such as detrusor overactivity are presumably equally important factors, and in general overlap in any single individual. Even in patients with urodynamically proven benign prostatic obstruction (BPO) the association between symptoms, quality of life, and objective urodynamic parameters remains weak. Clearly the mechanisms involved are interactive: storage symptoms suggestive of an overactive bladder $(\mathrm{OAB})$ increase with the degree of outflow obstruction [10], but bothersome LUTS persist in $20-40 \%$ of patients even after surgical correction of urodynamically confirmed BPO [11].
The patient consulting his doctor because of LUTS primarily seeks relief from his symptoms, but he also worries about further deterioration and complications requiring more invasive treatment such as surgery. This is not without foundation; LUTS assumed to be caused by BPH are progressive over time $[9,12]$ and the overall risk of acute urinary retention in population studies has been estimated at up to $23 \%$ for an average 60-year-old man if he survives another 20 years [13].

In view of the high prevalence of bothersome LUTS the diagnostic approach to the problem has to be fairly simple and straightforward. In general, a thorough history (with quantification of symptoms and quality of life issues; IPSS), a voiding chart (the physician should rule out nocturia, polyuria, and polydipsia), physical examination (with digital rectal examination of the prostate), urinalysis, determination of serum prostate-specific antigen (PSA), ultrasonography of the bladder, prostate, upper urinary tract (with determination of postvoid residual urine), and uroflowmetry provide all information needed for therapeutic decisions, at least on a nonsurgical level [2]. In men $>50$ years of age with an IPSS $>7$, no evidence of excessive nocturia, an enlarged prostate, maximum urinary flow rates $<12 \mathrm{~mL} / \mathrm{sec}$, and postvoid residual urine $<150 \mathrm{~mL}$, BPO resulting from prostatic enlargement is the most likely cause of the problem [14]. Serum PSA levels $>1.5 \mathrm{ng} / \mathrm{mL}$ have also proven fairly reliable surrogate markers of BPE once cancer is excluded [15]. Prostate volume and serum PSA are the most reliable prognosticators for the risk of symptom progression and the occurrence of complications such as acute urinary retention or the need for surgery [16].

Mild LUTS (IPSS $\leq 7$ ) can usually be managed with simple lifestyle advice, such as avoiding excessive fluid intake and moderating caffeine and alcohol consumption [17]. With an 
IPSS $>7$, consistent with moderate-to-severe LUTS, and clinical findings as described above, medical therapy becomes the first line of management $[6,18,19]$.

\section{METHODS}

The findings presented here are an interpretation of the present literature, and not the result of a systematic literature search by the author, which also reflects the situation of most guidelines on this topic $[6,18,19]$.

\section{DISCUSSION}

\section{Single-Agent Therapy}

\section{Alpha-1 Adrenoceptor Antagonists (Alpha-1 Blockers)}

Contraction of the smooth muscle of the prostate and bladder neck by endogenously released noradrenaline is primarily regulated by alpha-1A adrenoceptors, although alpha-1B and alpha-1D subtypes in the bladder and nervous system may also play a role [20, 21]. Blocking these receptors with alpha-1 blockers results in rapid reduction of symptoms by approximately $30-40 \%$ and improvement of flow rates by approximately $20 \%$, but disease progression is not avoided in the long term and there is no decrease in prostate volume or the likelihood of acute urinary retention $[6,9,22]$.

The therapeutic efficacy of all alpha-1 blockers currently licensed for the treatment of LUTS assumed to be caused by BPH appears fairly similar [23, 24], but their adverse effect profiles differ significantly, apparently due to their variable alpha-1 receptor subselectivity. Older agents, such as doxazosin and terazosin, also affect alpha-1B adrenoceptors in blood vessels and dosage has to be titrated according to individual tolerance. Alfuzosin, tamsulosin, and silodosin have less vasodilating effects and hence cause less asthenia, dizziness, and orthostatic hypotension. There is no significant impact on libido or erectile function, but tamsulosin and in particular silodosin may cause an absence of ejaculation, apparently due to a distinctly higher specificity to alpha-1A receptors [25]. Alpha-1 blockers, in particular tamsulosin, have been shown to cause intraoperative floppy iris syndrome at cataract surgery; therefore, they should be stopped well ahead of the procedure, and the ophthalmologist informed [26].

It is, at present, common consensus in major guidelines that alpha-1 blockers should be offered to men with moderate-to-severe LUTS based on level 1a evidence $[6,18,19]$

\section{5-alpha-Reductase Inhibitors}

$\mathrm{BPH}$ causing prostatic enlargement is androgen driven and at the cellular level this is mainly mediated by dihydrotestosterone (DHT). Testosterone is converted to DHT by the nuclearbound steroid enzyme 5-alpha reductase. If blocked, this mechanism is interrupted without impairing androgen activity outside of the prostate. 5-alpha reductase exists in two isoenzymes; type 2 is predominantly expressed in benign prostatic tissues and type 1 mainly in skin and liver, but also in prostate cancer cells [27-29].

Two 5-alpha-reductase inhibitors (5-ARIs) are approved for the treatment of LUTS considered to be caused by BPE from BPH, finasteride, and dutasteride. Finasteride blocks only the type 2 isoenzyme and reduces serum DHT at a dosage of $5 \mathrm{mg} /$ day by approximately $70 \%$. Dutasteride inhibits both isoenzymes and at a dose of $0.5 \mathrm{mg} /$ day decreases serum DHT levels by more than $90 \%[27,28]$. Inactivation of the androgen receptor results in apoptosis of prostate epithelial cells. Within 6 months, PSA levels fall by approximately 50\% and, by approximately 12 months, prostate volume 
decreases by $18-28 \%$ [30]. This is paralleled by an improvement in LUTS after approximately 9 months of treatment, with gradually improving flow rates [31-33]. A direct head-to-head comparison of finasteride and dutasteride with a follow-up of 12 months showed no difference in efficacy [34]. In the Medical Therapy of Prostatic Symptoms (MTOPS) trial, finasteride was inferior to doxazosin in preventing symptom progression at a mean follow-up of 4.5 years [9]. In contrast, dutasteride monotherapy in the Combination of Avodart and Tamsulosin (CombAT) trial proved more effective than tamsulosin monotherapy at 4 years, with an increasing advantage over time after 15 months of therapy (Fig. 1) [35-37]. The two studies are not fully comparable, as primary endpoints and the alpha- 1 blockers used for comparison were different and in spite of similar mean LUTS scores at baseline CombAT patients were at higher risk of progression because of significantly higher baseline prostate volumes and PSA levels. In both studies, 5-ARI therapy achieved a dramatic reduction of acute urinary retention rates and the need for surgery, which was not observed with alphablocker monotherapy. The impact on symptoms, flow rates, and the reduction of acute urinary retention was most pronounced in patients with the highest prostate volume and PSA levels, thus defining patients that are at highest risk of progression and complications, and who clearly profit most from 5-ARIs [37-40].

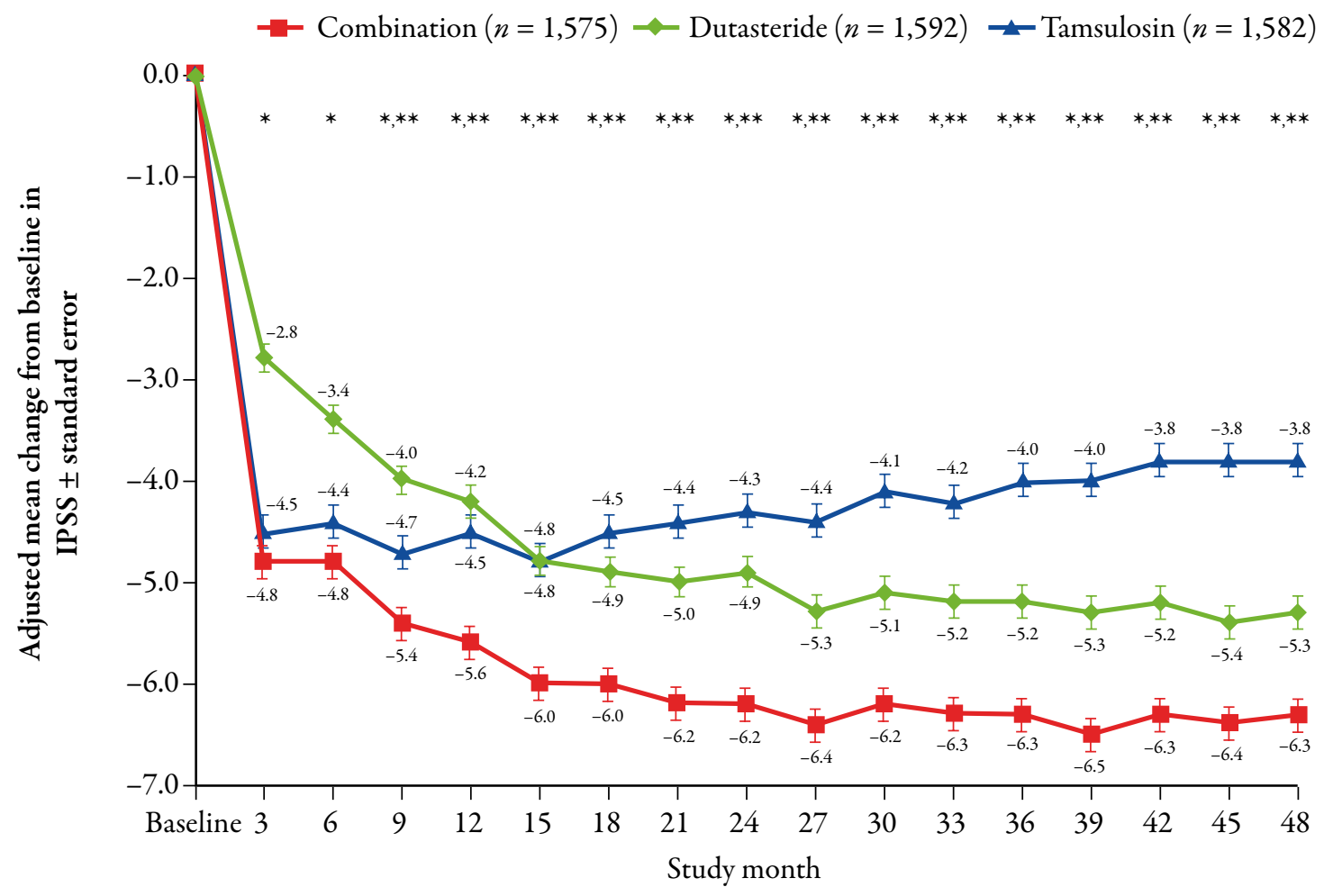

Fig. 1 CombAT study: Mean adjusted change in International Prostate Syndrome Score (IPSS; plus or minus standard error) from baseline by visit and treatment group. Reproduced with permission from Montorsi F, Roehrborn C, Garcia-Penit J, et al. The effects of dutasteride or tamsulosin alone and in combination on storage and voiding symptoms in men with lower urinary tract symptoms (LUTS) and benign prostatic hyperplasia (BPH): 4-year data from the Combination of Avodart and Tamsulosin (CombAT) study. BJU Int. 2011;107:1426-31. ${ }^{*} P<0.001$ for combination versus tamsulosin. ${ }^{* *} P<0.001$ for combination versus dutasteride 
5-ARIs are generally well tolerated. The most common adverse events observed in placebocontrolled studies were loss of libido and erectile dysfunction in approximately $5 \%$ of patients and, less commonly, abnormal ejaculation [9, 32, 33]. The magnitude of these problems has to be seen against frequent sexual dysfunction in patients with LUTS. In a large population-based study $18 \%$ of men $70-80$ years of age with moderateto-severe LUTS reported severe erectile dysfunction [41]. A small percentage of men develop gynecomastia [31, 36, 42, 43], but a statistically significant incidence of malignant breast tumors has not been observed in any prospective controlled 5-ARI trials.

In prospective, placebo-controlled chemoprevention trials, both finasteride [44] and dutasteride [45] reduced the incidence of low-grade prostate cancer, but the systematic, study-driven biopsies revealed a slightly higher incidence of high-grade, Gleason score 8-10 prostate cancer in the 5-ARI arms. This was not observed in real-life studies in patients being treated for LUTS, such as the CombAT trial [36], where biopsies were only performed when clinically indicated. Plausible explanations for the higher detection of high grade cancers in the chemoprevention trials are the better diagnostic accuracy of biopsies in smaller prostates, an increased sensitivity of PSA testing in patients on 5-ARIs, and possibly a more pronounced effect of 5-ARI on low-grade than on high-grade cancers $[46,47]$. Patients should remain under surveillance in this context. The key to this issue is understanding the altered PSA dynamics in patients on 5-ARIs. PSA levels decrease continuously with long-term 5-ARI medication, rendering the simple "doubling rule" (to compare PSA levels to the values of men not on 5-ARIs) unreliable [46, 47]. A first PSA measurement should be obtained after 6 months of 5-ARI medication and this becomes the new baseline value for future comparison. PSA is monitored at regular intervals thereafter (in general every 6 months) and any confirmed increase from the lowest value measured thereafter, a "nadir," should be considered a warning flag of possible cancer and trigger the appropriate diagnostic measures [48].

\section{Antimuscarinics}

Although older men with BPE report a higher prevalence of voiding than storage symptoms, the latter are more bothersome and tend to affect quality of life more profoundly [5]. Given the high prevalence of concomitant detrusor overactivity and $\mathrm{OAB}$ in men with BPE [10] it would seem logical to treat men with predominant storage symptoms with muscarinic receptor antagonists, i.e., bladderspecific drugs. The obvious concern with this approach is that antimuscarinics improve urgency, but lower voiding pressure, increase postvoid residual, and may ultimately trigger acute urinary retention. Prospective, controlled studies with antimuscarinic monotherapy in men with urodynamically proven bladder outlet obstruction and $\mathrm{OAB}$ have not confirmed these risks, but usually only showed improvement in subgroup analyses of symptoms of no, or only marginal, clinical significance [49-51]. Patients with high postvoid residual, low flow rates, and severe obstruction were usually excluded in these studies and follow-up was limited to 6-12 weeks. Patients with small prostates and/or PSA levels $<1.3 \mathrm{ng} / \mathrm{mL}$ seem to benefit more [52], but there is general agreement that antimuscarinic monotherapy should be approached with caution in men with LUTS and BPE; close urologic surveillance is mandatory $[6,18,19]$.

\section{Phosphodiesterase-5 Inhibitors}

Prospective, placebo-controlled, randomized trials have shown that phosphodiesterase-5 
inhibitors (PDE-5 Is) improve LUTS in men assumed to be caused by BPO [53, 54]. Biologically active PDE-5 is expressed in the musculature of the bladder neck, prostatic urethra, and prostate [55], and its inactivation had been postulated to relieve outflow obstruction until this was disproven by Dmochowski et al [56]. This has not really been confirmed urodynamically, and more complex mechanisms affecting an increased bladder/prostate afferent activity may also play a role [56]. A recent systematic analysis of seven prospective studies comparing PDE-5 Is monotherapy versus placebo in $>2,000$ men demonstrated consistent improvement of LUTS and erectile function, but no change in flow rates [57]. Symptom improvement was similar across all PDE-5 Is and dosages studied. Younger men with lower body mass index and more severe LUTS seemed to benefit most. Adverse events were consistent with those documented in the treatment of erectile dysfunction and mainly consisted of flushing, gastroesophageal reflux, dyspepsia, and headache [57]. All studies were limited by short duration, usually 12 weeks, and the lack of adequately powered direct comparison to approved agents, such as alpha-1 blockers $[57,58]$. Although PDE-5 Is are already approved for the treatment of male LUTS in the US and Europe, recent guidelines still suggest that they be used cautiously $[6,18,19]$.

\section{Phytotherapy}

A wide spectrum of plant extracts are being marketed for the treatment of LUTS across the world. Their pharmacokinetic properties are highly variable, in general poorly defined, and rarely studied in adequately powered prospective trials. The European Association of Urology guidelines on the management of nonneurogenic male LUTS analyzed in detail the phytotherapeutic products marketed in Europe and concluded that 'no phytotherapeutic agent has been shown to significantly reduce prostate size and no trial has proven reduction of bladder outlet obstruction or decreased disease progression' [6].

\section{Combination Therapy}

Given the complex and multifactorial etiology of LUTS and clear limitations of all single-agent approaches combining drugs with different modes of action to achieve synergistic effects appears a logical development [58].

\section{Alpha-1 Blockers and 5-ARIs}

Alpha-1 blockers provide rapid symptom improvement within weeks, but cannot prevent disease progression and acute urinary retention. 5-ARIs achieve the latter, but take months to alleviate symptoms. Combining the two achieves both treatment objectives of rapid relief of symptoms and reducing the risk of progression. Long-term treatment is prerequisite, the advantage of combining the two classes of agents has only been demonstrated with treatment $>12$ months, and the advantage becomes more pronounced the longer it is administered $[9,36,58]$. Patients at higher risk of progression, e.g., with larger prostates and/or higher PSA levels, profit more.

The CombAT trial compared tamsulosin versus dutasteride versus the combination of both in patients with $\geq 12$ IPSS, prostate volumes $\geq 30 \mathrm{~mL}$, and serum PSA $\geq 1.5 \mathrm{ng} / \mathrm{mL}$. Combination therapy resulted in better symptom improvement than tamsulosin monotherapy already after 9 months of therapy, and the difference increased with ongoing treatment (Fig. 1) [35-37, 39]. Similar advantages were seen in improvements of storage and voiding IPSS subscales and flow rates and time to symptom progression [37, 39]. Urinary retention rates were lower with combination therapy than with 
tamsulosin monotherapy already after 8 months, and continued to diverge linear to a relative reduction of $68 \%$ at 4 years $[35,36]$. Patients with larger prostates at baseline clearly profited most, and symptom improvement was superior when comparing tamsulosin monotherapy with combination therapy from month 21 in the lowest volume tertile $\left(30-42 \mathrm{~cm}^{3}\right)$, from month 6 in the middle volume tertile, and from month 3 in the highest volume tertile $\left(>58 \mathrm{~cm}^{3}\right)[35,39]$. In the MTOPS trial, the combination of doxazosin and finasteride was compared to monotherapy and placebo. Patients included in the study had lower prostate volumes and PSA levels at baseline than in the CombAT trial, but the results were similar; combination therapy was significantly more effective in preventing disease progression, with the advantages more pronounced in the patients with larger prostates at baseline [9, 38, 40].

The adverse events observed with combination therapy are additive, and as a consequence more common than with either single agent. They reflect the adverse event profile of each class of agents. Serious adverse events were, however, rare $(<1 \%)$ in these studies, and comparable in the combination and monotherapy arms, with similar study withdrawal rates $[9,36]$.

Recent guidelines recommend the combination of an alpha-1 blocker and an 5-ARI as first-line treatment of men with moderate-to-severe LUTS and an enlarged prostate, although the definition of "enlarged" varies from no precise definition [6] to prostate volumes $>30-40 \mathrm{~mL}[18,19]$. Differing opinions on this issue only exist on the lower cut-off value of prostate volume above which this combination becomes the first-line therapy. A posthoc subanalysis of MTOPS data suggested advantages over alpha-1 blocker monotherapy already at baseline prostate volumes $>25$ cc [40]. In the CombAT trial, patients had to have a prostate volume $>30 \mathrm{~mL}$ to be admitted to the study; combination therapy reduced symptom deterioration across all baseline subgroups, but this did not reach statistical significance at prostate volumes $<40 \mathrm{~mL}$ [39]. With an inherent variation of prostate volume measurements by ultrasonography of about $\pm 15 \%$ a precise threshold is clinically probably overstated. Therefore, the larger the prostate the higher the risk of disease progression and the more pronounced the benefits of combining an alpha-1 blocker with an ARI with long-term treatment.

\section{Alpha-1 Blockers and Antimuscarinics}

In the first major prospective randomized trial by Kaplan et al., the combination of tolterodine and tamsulosin was compared against either single agent and placebo in patients with an IPSS $\geq 12$ and explicit bothersome storage symptoms ( $\geq 3$ urgency episodes per day) [50]. Total IPSS and the patient-reported treatment benefit after 12 weeks of therapy showed significant improvement in the combination arm, whereas tamsulosin alone only improved the total IPSS and tolterodine alone showed no improvement of either [50]. The improvement in quality of life with combination therapy was dominated by the improvement in storage symptoms, in particular 24 -h voiding frequency. Similar messages come from studies in which an antimuscarinic agent is added to an alpha-1 blocker, usually after an insufficient response; storage symptoms improve at no increased risk of acute urinary retention [59-61]. All of these studies tended to include patients with predominantly storage symptoms and excluded patients with significant postvoid residual and/or low flow rates at baseline. Patient numbers are often too small for valid statistical comparison of the different treatment arms and follow-up is usually short. The typical adverse events of anticholinergic medication, such as dry mouth 
and constipation, usually also resulted in higher withdrawal rates in the combination arms than in alpha-blocker monotherapy or placebo add-on arms [52, 58].

\section{Alpha-1 Blocker and PDE-5 Is}

Combining an alpha-1 blocker with sildenafil/ tadalafil has been shown to improve symptom scores, flow rates, and erectile function $[53,57,58]$. Side effects were only marginally increased. Both studies were only powered to compare the results to baseline, and not between groups. Overall, the data are insufficient to document a clear advantage of this combination in comparison to alpha-1 blocker monotherapy in the typical LUTS patient. Nevertheless, being able to add a PDE-5 inhibitor to an alpha-1 blocker without major problems, and possibly advantages, is an important message in this population given that over 50\% (approximately) patient group have problems with erectile dysfunction [41].

\section{CONCLUSION}

In men with moderate-to-severe LUTS and a prostate volume $>30-40 \mathrm{~mL}$ and/or serum PSA $>1.5 \mathrm{ng} / \mathrm{mL}$, the combination of an alpha-1 blocker with a 5-ARI should be firstline treatment today. In men with prostates $<30 \mathrm{~mL}$ at baseline, the issue whether the symptoms are really caused by bladder outflow obstruction becomes more central. Once other obvious reasons for LUTS, such as urinary tract infection, bladder tumors, urethral strictures, obvious neurogenic dysfunction, and postvoid residuals $>250 \mathrm{cc}$, have been ruled out a 4-6-week trial of therapy with an alpha-1 blocker appears a logical approach. If IPSS does not improve, and storage symptoms prevail, an $\mathrm{OAB}$ appears more likely as causative factor and antimuscarinics are the next step.
Based on available data this is recommended as add-on medication to the alpha- 1 blocker. With no improvement, or increasing postvoid residual the diagnostic algorithm needs to be revisited and more extensive urodynamic evaluation may be needed.

\section{ACKNOWLEDGMENTS}

Prior to peer review GlaxoSmithKline were offered the opportunity to review this paper for scientific accuracy. No writing assistance, other editorial involvement, or financial support was provided by the manufacturer in the production of this manuscript. Dr. Michael Marberger is the guarantor for this article, and takes responsibility for the integrity of the work as a whole.

Conflict of interest. Dr. Michael Marberger declares the following financial disclosures: he is/was consultant/advisor/investigator/ speaker/trial participant for Allergan, Astellas, GlaxoSmithKline, GP Pharm, Janssen, Millennium, MSD, Recordati, Sotio, US-HIFU, Richard Wolf $\mathrm{GmbH}$, and is a member of Advisory Boards for Astellas, GlaxoSmithKline, and MSD.

Open Access. This article is distributed under the terms of the Creative Commons Attribution Noncommercial License which permits any noncommercial use, distribution, and reproduction in any medium, provided the original author(s) and source are credited.

\section{REFERENCES}

1. Platz EA, Joshu CE, Mondul AM, Peskoe SB, Willett WC, Giovannucci E. Incidence and progression of lower urinary tract symptoms in a large prospective cohort of United States men. J Urol. 2012;188: 496-501.

2. Oelke M, Burger M, Castro-Diaz D, et al. Diagnosis and medical treatment of lower urinary tract symptoms in adult men: applying specialist guidelines in clinical practice. BJU Int. 2012;110:710-8. 
3. Naslund MJ, Gilsenan AW, Midkiff KD, Bown A, Wolford ET, Wang J. Prevalence of lower urinary tract symptoms and prostate enlargement in the primary care setting. Int J Clin Pract. 2007;61:1437-45.

4. Coyne KS, Sexton CC, Irwin DE, Kopp ZS, Kelleher CJ, Milsom I. The impact of overactive bladder, incontinence and other lower urinary tract symptoms on quality of life, work productivity, sexuality and emotional well-being in men and women: results from the EPIC study. BJU Int. 2008;101:1388-95.

5. Sexton CC, Coyne KS, Kopp ZS, et al; EpiLUTS Team. The overlap of storage, voiding and postmicturition symptoms and implications for treatment in the USA, UK and Sweden: EpiLUTS. BJU Int. 2009;103:12-23.

6. Oelke M, Bachmann A, Descazeaud A, et al. Guidelines on the management of male lower urinary tract symptoms (LUTS), incl. benign prostatic obstruction (BPO). European Association of Urology, Update February 2012. Available at: www.uroweb.org/gls/pdf/12_Male_LUTS_LR.pdf. Accessed Mar 112013.

7. Chapple CR, Roehrborn CG. A shifted paradigm for the further understanding, evaluation and treatment of lower urinary symptoms in men. Eur Urol. 2006;49:651-8.

8. Carballido J, Fourcade R, Pagliarulo A, et al. Can benign prostatic hyperplasia be identified in the primary care setting using only simple tests? Results of the Diagnosis IMprovement in PrimAry Care Trial. Int J Clin Pract. 2011;65:989-96.

9. McConnell JD, Roehrborn CG, Bautista OM, et al; Medical Therapy of Prostatic Symptoms (MTOPS) Research Group. The long-term effect of doxazosin, finasteride, and combination therapy on the clinical progression of benign prostatic hyperplasia. N Engl J Med. 2003;349:2387-98.

10. Oelke M, Baard J, Wijkstra H, de la Rosette JJ, Jonas U, Höfner K. Age and bladder outlet obstruction are independently associated with detrusor overactivity in patients with benign prostatic hyperplasia. Eur Urol. 2008;54:419-26.

11. Seki N, Yunoki T, Tomoda T, Takei M, Yamaguchi A, Naito S. Association among the symptoms, quality of life and urodynamic parameters in patients with improved lower urinary tract symptoms following a transurethral resection of the prostate. Neurourol Urodyn. 2008;27:222-5.
12. Emberton M, Fitzpatrick JM, GarciaLosa M, Qizilbash N, Djavan B. Progression of benign prostatic hyperplasia: systematic review of the placebo arms of clinical trials. BJU Int. 2008;102:981-6.

13. Jacobsen SJ, Jacobsen DJ, Girman CJ et al. Natural history of prostatism: risk factors for acute urinary retention. J Urol. 1997;158:481-7.

14. Madersbacher S, Pycha A, Klingler CH, Schatzl G, Marberger M. The International Prostate Symptom score in both sexes: a urodynamics-based comparison. Neurourol Urodyn. 1999;18:173-82.

15. Roehrborn CG, McConnell J, Bonilla J, et al. Serum prostate specific antigen is a strong predictor of future prostate growth in men with benign prostatic hyperplasia. PROSCAR long-term efficacy and safety study. J Urol. 2000;163:13-20.

16. Roehrborn CG, Malice M, Cook TJ, Girman CJ. Clinical predictors of spontaneous acute urinary retention in men with LUTS and clinical BPH: a comprehensive analysis of the pooled placebo groups of several large clinical trials. Urology. 2001;58:210-6.

17. Brown CT, Yap T, Cromwell DA, et al. Self management for men with lower urinary tract symptoms: randomised controlled trial. BMJ. 2007;334:25.

18. McVary KT, Roehrborn CG, Avins AL, et al. Update on AUA guideline on the management of benign prostatic hyperplasia. J Urol. 2011;185:1793-803.

19. NICE clinical guidelines. Lower urinary tract symptoms: The management of lower urinary tract symptoms in men. Available at: http:// publications.nice.org.uk/lower-urinary-tractsymptoms-cg97. Accessed Mar 112013.

20. Schwinn DA, Roehrborn CG. Alpha1-adrenoceptor subtypes and lower urinary tract symptoms. Int J Urol. 2008;15:193-9.

21. Barenddrecht MM, Abrams P, Schumacher $H$, et al. Do alpha1-adrenoceptor antagonists improve lower urinary tract symptoms by reducing bladder outlet obstruction? Neurourol Urodyn. 2008;27:226-30.

22. Roehrborn CG. Alfuzosin $10 \mathrm{mg}$ once daily prevents overall clinical progression of benign prostatic hyperplasia, but not acute urinary retention: results of a 2-year placebo-controlled study. BJU Int. 2006;97:734-41. 
23. Djavan B, Chapple C, Milani S, Marberger M. State of the art on efficacy and tolerability of alpha1adrenoceptor antagonists in patients with lower urinary tract symptoms suggestive of benign prostatic hyperplasia. Urology. 2004;64:1081-8.

24. Nickel JC, Sander S, Moon TD. A meta-analysis of the vascular-related safety profile and efficacy of alpha-adrenergic blockers for symptoms related to benign prostatic hyperplasia. Int J Clin Pract. 2008;62:1547-59.

25. Chapple CR, Montorsi F, Tammela JL, Wirth M, Kodewijn E, Fernandez EF. Silodosin therapy for lower urinary tract symptoms in men with suspected benign prostatic hyperplasia: results from an international, randomized, double-blind, placebo- and active-controlled trial performed in Europe. Eur Urol. 2011;59:342-52.

26. Chang DF, Campbell JR. Intraoperative floppy iris syndrome associated with tamsulosin. J Cataract Refract Surg. 2005;31:664-73.

27. Tindall DJ, Rittmaster RS. The rationale for inhibiting 5alpha-reductase isoenzymes in the prevention and treatment of prostate cancer. J Urol. 2008;179:1235-42.

28. Thomas LN, Lazier CB, Gupta R, et al. Differential alterations in 5alpha-reductase type 1 and type 2 levels during development and progression of prostate cancer. Prostate. 2005;63:231-9.

29. Clark RV, Hermann DJ, Cunningham GR, Wilson TH, Morrill BB, Hobbs S. Marked suppression of dihydrotestosterone in men with benign prostatic hyperplasia by dutasteride, a dual 5alpha-reductase inhibitor. J Clin Endocrinol Metab. 2004;89: 2179-84.

30. Andriole G, Bruchovsky N, Chung LW, et al. Dihydrotestosterone and the prostate: the scientific rationale for 5alpha-reductase inhibitors in the treatment of benign prostatic hyperplasia. J Urol. 2004;172:1399-403.

31. McConnell JD, Bruskewitz R, Walsh P, et al. The effect of finasteride on the risk of acute urinary retention and the need for surgical treatment among men with benign prostatic hyperplasia. Finasteride Long-Term Efficacy and Safety Study Group. N Engl J Med. 1998;338:557-63.

32. Marberger MJ. Long-term effects of finasteride in patients with benign prostatic hyperplasia: a double-blind, placebo-controlled, multicenter study. PROWESS Study Group. Urology. 1998;51:677-86.
33. Debruyne F, Barkin J, van Erps P, Reis M, Tammela LJ, Roehrborn C; ARIA3001, ARIA3002 and ARIB3003 Study Investigators. Efficacy and safety of long-term treatment with the dual 5 alphareductase inhibitor dutasteride in men with symptomatic benign prostatic hyperplasia. Eur Urol. 2004;46:488-94.

34. Nickel JC, Gilling P, Tammela TL, Morrill B, Wilson $\mathrm{TH}$, Rittmaster RS. Comparison of dutasteride and finasteride for treating benign prostatic hyperplasia: the Enlarged Prostate International Comparator Study (EPICS). BJU Int. 2011;108: 388-94.

35. Roehrborn CG, Siami P, Barkin J, et al. The influence of baseline parameters on changes in international prostate symptom score with dutasteride, tamsulosin, and combination therapy among men with symptomatic benign prostatic hyperplasia and an enlarged prostate: 2-year data from the CombAT study. Eur Urol. 2009;55: 461-71.

36. Roehrborn CG, Siami P, Barkin J, et al. The effects of combination therapy with dutasteride and tamsulosin on clinical outcomes in men with symptomatic benign prostatic hyperplasia: 4-year results from the CombAT study. Eur Urol. 2010;57:123-31.

37. Montorsi F, Roehrborn C, Garcia-Penit J, et al. The effects of dutasteride or tamsulosin alone and in combination on storage and voiding symptoms in men with lower urinary tract symptoms (LUTS) and benign prostatic hyperplasia (BPH):4-year data from the Combination of Avodart and Tamsulosin (CombAT) study. BJU Int. 2011;107:1426-31.

38. Crawford ED, Wilson SS, McConnell JD, et al. Baseline factors as predictors of clinical progression of benign prostatic hyperplasia. J Urol. 2006;175:1422-7.

39. Roehrborn CG, Barkin J, Siami P, et al. Clinical outcomes after combined therapy with dutasteride plus tamsulosin or either monotherapy in men with benign prostatic hyperplasia (BPH) by baseline characteristics: 4-year results from the randomized, double-blind Combination of Avodart and Tamsulosin (CombAT) trial. BJU Int. 2011;107:946-54.

40. Kaplan SA, Lee JY, Meehan AG, Kusek JW; MTOPS Research Group. Long-term treatment with finasteride improves clinical progression of benign prostatic hyperplasia in men with an enlarged versus a smaller prostate: data from the MTOPS trial. J Urol. 2011;185:1369-73. 
41. Rosen R, Altwein J, Boyle P, et al. Lower urinary tract symptoms and male sexual dysfunction: the multinational survey of the aging male (MSAM-7). Eur Urol. 2003;44:637-49.

42. Green L, Wysowski DK, Fourcroy JL. Gynecomastia and breast cancer during finasteride therapy. $\mathrm{N}$ Engl J Med. 1996;335;823.

43. Lee SC, Ellis RJ. Male breast cancer during finasteride therapy. J Natl Cancer Inst. 2004;96:338-9.

44. Thompson IM, Goodman PJ, Tangen CM, et al. The influence of finasteride on the development of prostate cancer. N Engl J Med. 2003;349:215-24.

45. Andriole GL, Bostwick DG, Brawley OW, et al; REDUCE Study Group. Effect of dutasteride on the risk of prostate cancer. $\mathrm{N}$ Engl J Med. 2010;362:1192-202.

46. Thompson IM, Chi C, Ankerst DP, et al. Effect of finasteride on the sensitivity of PSA for detecting prostate cancer. J Natl Cancer Inst. 2006;98: 1128-33.

47. Andriole GL, Bostwick D, Brawley OW, et al; REDUCE Study Group. The effect of dutasteride on the usefulness of prostate specific antigen for the diagnosis of high grade and clinically relevant prostate cancer in men with a previous negative biopsy: results from the REDUCE study. J Urol. 2011;185:126-31.

48. Marberger M, Freedland SJ, Andriole GL, et al. Usefulness of prostate-specific antigen (PSA) rise as a marker of prostate cancer in men treated with dutasteride: lessons from the REDUCE study. BJU Int. 2012;109:1162-9.

49. Abrams P, Kaplan S, De Koning Gans HJ, Millard R. Safety and tolerability of tolterodine for the treatment of overactive bladder in men with bladder outlet obstruction. J Urol. 2006;175: 999-1004.

50. Kaplan SA, Roehrborn CG, Rovner ES, Carlsson M, Bavendam T, Guan Z. Tolterodine and tamsulosin for treatment of men with lower urinary tract symptoms and overactive bladder: a randomized controlled trial. JAMA. 2006;296:2319-28.

51. Roehrborn CG, Kaplan SA, Kraus SR, Wang JT, Bavendam T, Guan Z. Effects of serum PSA on efficacy of tolterodine extended release with or without tamsulosin in men with LUTS, including OAB. Urology. 2008;72:1061-7.
52. Chapple C. Antimuscarinics in men with lower urinary tract symptoms suggestive of bladder outlet obstruction due to benign prostatic hyperplasia. Curr Opin Urol. 2010;20:43-8.

53. McVary KT, Roehrborn CG, Kaminetsky JC, et al. Tadalafil relieves lower urinary tract symptoms secondary to benign prostatic hyperplasia. J Urol. 2007;177:1401-7.

54. Oelke M, Guiliano F, Mirone V, Xu L, Cox D, Viktrup L. Monotherapy with tadalafil or tamsulosin similarly improved lower urinary tract symptoms suggestive of benign prostatic hyperplasia in an international, randomised, parallel, placebo-controlled clinical trial. Eur Urol. 2012;61:17-25.

55. Fibbi B, Morelli A, Vignozzi L, et al. Characterization of phosphodiesterase type 5 expression and functional activity in the human male lower urinary tract. J Sex Med. 2010;7:59-69.

56. Dmochowski R, Roehrborn C, Klise S, Xu L, Kaminetsky J, Kraus S. Urodynamic effects of once daily tadalafil in men with lower urinary tract symptoms secondary to clinical benign prostatic hyperplasia: a randomized, placebo controlled 12week clinical trial. J Urol. 2010;183:1092-7.

57. Gacci M, Corona G, Salvi M, et al. A systematic review and meta-analysis on the use of phosphodiesterase 5 inhibitors alone or in combination with $\alpha$-blockers for lower urinary tract symptoms due to benign prostatic hyperplasia. Eur Urol. 2012;61:994-1003.

58. Füllhase C, Chapple CH, Cornu JN, et al. Systematic review of combination drug therapy for nonneurogenic male lower urinary tract symptoms. Eur Urol. 2013; Jan 25 [Epub ahead of print].

59. Chung SD, Chang HC, Chiu B, Liao $\mathrm{CH}$, Kuo HC. The efficacy of additive tolterodine extended release for 1-year in older men with storage symptoms and clinical benign prostatic hyperplasia. Neurourol Urodyn. 2011;30:568-71.

60. Chapple C, Herschorn S, Abrams P, Sun F, Brodky M, Guan Z. Tolterodine treatment improves storage symptoms suggestive of overactive bladder in men treated with alpha-blockers. Eur Urol. 2009;56:534-41.

61. Yamaguchi O, Kakizaki H, Homma Y, et al. Solifenacin as add-on therapy for overactive bladder symptoms in men treated for lower urinary tract symptoms - ASSIST, randomized controlled study. Urology. 2011;78:126-33. 